\title{
The Provision and Finance of Long-term Care in the United Kingdom
}

\author{
by David K. Whynes*
}

\section{Introduction}

For some people, disability is an acute and relatively short-term condition, for example, the recovery to normal health following a road traffic accident. ${ }^{1}$ For others, the condition is chronic and is likely to necessitate long term care (LTC). LTC consists of the services to disabled individuals provided by others, in order that the former may continue to function at acceptable levels of quality of life. With chronic disability, LTC is normally a requirement until death, the intensity of care having to increase as the patient's condition deteriorates. Diseases and syndromes leading to long-term chronic disability include stroke, cancer, arthritis, HIV and dementia.

The simple facts of demography in the UK, and, for that matter, in the majority of Western countries, suggest an inevitable and significant increase in the prevalence of disability over the next few decades. Accordingly, there is likely to be an increased need for LTC and, assuming that this need is to be met, it will also have to be financed. In the UK at present, LTC is provided through a variety of mechanisms, both public and private, although the sheer scale of projected future need is likely to place considerable strains on existing institutional structures unless pre-emptive action is taken in the very near future.

\section{The prevalence of disability}

Empirical investigations into the prevalence of disability amongst the populations of industrialised nations consistently produce two broad conclusions. First, the prevalence of disabilities of any degree is higher in the older age cohorts; this is to be expected, given that the incidences of most of the diseases and syndromes causing disability are strongly associated with age. Second, for the elderly population, the proportion of severe, as opposed to

* Reader in Health Economics, Department of Economics University of Nottingham.

1 We shall take the term "disability" to refer to the condition of individuals who experience degrees of functional limitation on their activities of everyday life, for example, with respect to locomotion, dexterity, continence and personal hygiene, communication and intellectual capacity. 
minor, disabilities also tends to increase with age. In Great Britain, for example, a major survey conducted in the mid-1980s by the Office of Population Censuses and Surveys (OPCS) indicated a prevalence of disability amongst males aged $30-39$ years of $4.2 \%$. This rises to $24.3 \%$ for the $60-69$ age group and to $72.5 \%$ for those over 80 years of age. For females, the prevalence for those in their thirties and sixties is $4.7 \%$ and $23.7 \%$, respectively, and $71.0 \%$ for the 80-89 age cohort. This survey employed a 10-point scale to measure severity of disability and, for males in their sixties, $20.9 \%$ of cases were rated as being in the five most severe states. This proportion rises to $42.0 \%$ for males over 80 years of age. For females, the corresponding proportions are $26.4 \%$ and $52.6 \%$, respectively (Martin, Meltzer et al., 1988).

Barring unforeseen disasters, we should expect that, over the next four decades, the populations of virtually all Western economies will age. Population ageing is due, first, to the progressive increases in life expectancy which generally follow the growth in economic prosperity and advances in medical science. Second, the birth cohorts of the two decades of post-war prosperity will gradually work their way through the demographic structure, cohorts large relative to those emerging in more recent times. By implication, the number of cases of age-related diseases and syndromes giving rise to disabilities will also increase.

It is projected that, between 1991 and 2031, the proportion of persons aged 65 and over in Britain will increase from $16 \%$ to $23 \%$, whilst the numbers of those aged 80 years and over will double (Office of Population Censuses and Surveys, 1993). To estimate the impact of demographic change on LTC needs, Nuttall et al undertook an exercise combining disability prevalence data from the OPCS survey with published population projections (Nuttall, Blackwood et al., 1994). Two points about their method should be noted. First, progressive improvements in both mortality and morbidity rates amongst the disabled were incorporated, based on the assumptions of increased life expectancy and medical advances. Second, the ten OPCS severity categories of the original survey were collapsed into four, which the authors identified as entailing low, moderate, regular and continuous levels of LTC. For 1991, they estimated that 6.4 million adults exhibited some degree of disability, the proportions in the four severity categories being $30,32,24$ and $14 \%$ respectively. Tlieir estimate rose to 8.5 million disabled adults by 2031 , an increase of $33 \%$, and virtually all of this increase occurred in the last three decades. The growth for low, moderate, regular and continuous care needs was approximately $21,23,39$ and $99 \%$, respectively. For adults over 60 years of age, the projected growth in disability numbers was even higlier than the average, at $50 \%$.

An equivalent methodology can be used to forecast specific causes of disability. Consider, for example, the case of dementia. Of recent prevalence estimates, those most widelyaccepted have beell made by Hofman $e t$ al, using pooled date from a number of European countries (Hofman, Rocca et al., 1991). The Hofman data suggest all age-related risk factor rising from $1.6 \%$ for the $65-69$ age group to $33.6 \%$ for those aged 90 years and above. Based on these prevalence estimates, the projected demographic structure for England and Wales (Office of Population Censuses and Surveys, 1993) can be used to predict the probable number of cases to be expected in these countries over the next four decades. It transpires that the 560,000 cases in 1991 will translate to almost 1.1 million cases by the year 2031 . For the first 20 years, prevalence growth will be approximately linear, at around $1.3 \%$ per annum. Thereafter, growth will be exponential, also at approximately $1.3 \%$ per annum. 


\section{The supply of LTC}

The potential settings for the provision of LTC in the UK at present are many and various; broadly speaking, they consist of the following:

(i) Private household, living alone. Such a person may be either employed or a recipient of state welfare benefits. He or she will typically have access to varying degrees of support from the public, private or voluntary sectors, in the form of, for example, general practitioner supervision, community nursing, out-patient hospital visits, "home help" (care assistants), a laundry service and the delivery of pre-cooked meals ("meals-onwheels"). Day-care centres might also be available.

(ii) Private household, living with informal carers. As for (i), support for the disabled individual will be available. Informal carers - spouse, family or friends - will also be eligible for additional social security benefits. Given that the informal care for a disabled person may, of itself, generate adverse health consequences for the carers (for example, stress or depression), facilities for "care for the carers" (respire care or family support) may be provided.

(iii) Residential home operated by the local authority, the private sector or the voluntary sector.

(iv) Nursing home operated by the local authority, the private sector or the voluntary sector. The nursing home is to be distinguished from the residential home in providing higher degrees of medical supervision.

(v) Hospital operated by the public or private sector.

According to the OPCS survey cited above, approximately $7 \%$ of disabled adults are living in residential establishments i.e. $93 \%$ - the vast majority - are living either alone or with informal carers. The precise form of LTC received by any given subject will depend upon a number of parameters (for example, the severity of the condition, wealth, income and family circumstances, the scope of local authority provision in the subject's area) and residential care will be more prevalent where disability is more severe. For example, according to a recent estimate (Schneider, Kavanagh et al., 1993) of the location of around 320,000 elderly individuals with "advanced cognitive impairment" in England, 37\% are presently cared for in some form of communal establishment. Of this group, 39\% dweil in local authority accommodation, $25 \%$ in private sector accommodation, $7 \%$ in voluntary sector accommodation, whilst $29 \%$ are in hospital. The remainder of the total $(63 \%)$ live in private households and, of these, one third (21\%) live alone.

Changes in the structure of the formal care of the disabled have been evident in recent years. The number of available non-acute hospital beds in Great Britain fell from 299,000 in 1977 to 172,000 in 1990, a decline of $42 \%$ (Office of Health Economics, 1992). Over the same period, the number of elderly residents in English residential homes increased by $59 \%$, from around 150,000 to approaching 240,000 . The growth by sector was markedly uneven, however. The number of residents in local authority homes declined by $10 \%$; local authorities offered $67 \%$ of all residential places in 1977 , but $38 \%$ in 1990 . The voluntary sector catered for some 25,000 residents in 1977 but only for 3,000 more by 1990 . Of the three, the private sector was the smallest in 1977 (15\% of residents), but the largest in 1990 ( $50 \%$ of residents) (Central Health Monitoring Unit, 1992). By 1992, the relative shares of the local authority, voluntary and private sectors had reached 30,13 and $57 \%$ respectively (Department of Health, 1993). These changes reflect, in large part, a prevailing government 
policy which favour both care in the community (Secretaries of State for Health, 1989) and the extension of private sector provision. These data partially disguise a distinction between provision and finance because, in earlier times, the private and voluntary sectors were heavily dependent upon local authority funding. In 1978, local authorities supported approximately 15,000 residents in the other sectors, although this figure has fallen below 5,000 by 1992 (Whynes, 1995).

Whether any given patient is currently receiving the form and level of LTC most appropriate to his or her condition remains a moot point. For example, one would intuitively incline to the view that subjects with the severest-possible disabilities would be best served in either residential establishments or in the company of informal carers, yet the OPCS survey found that $10 \%$ of such individuals were living alone. The economic circumstances of the disabled in Britain are presently far from ideal $-60 \%$ are obliged to claim safety net benefits from the state and nearly half do not have sufficient income to meet their basic household costs (Berthoud, lakey et al., 1993). Moreover, there is abundant evidence that, given the current level of formal care provision, informal carers are being obliged to bear sizeable emotional and economic costs which, were more formal care services to be available, they would not themselves chose to bear (Pearson, 1988; Levin, Sinclair et al., 1989; Parker, 1990). The quality of social services support for carers is highly variable on a regional basis(Audit Commission, 1991). In particular, informal care can entail an employment sacrifice in cases where the carer is of working age. In 1986, for example, $15 \%$ of women aged $50-59$ years who had left employment in the preceding three years had done so in order to care for a family member (Laczko and Phillipson, 1991) and the loss of family earnings must contribute to the burden of informal care. In comparison with the USA and many European Community states, the UK at present offers very limited scope for combining informal care with employment. In such countries, special leave allowances and continued social security support are more readily available. The employed-carer group has not been targeted in recent UK employment policy, because efforts have been directed principally towards the unemployed young (Laczko and Noden, 1993).

\section{The costs of LTC}

Forecasting the need for LTC is a simple exercise in comparison with estimating the costs. To begin with, there is no such thing as a "unit" of LTC, because disabilities of differing severity will require different modes of care. This having been said, a certain amount of information on the basic components of costs of LTC is available. According to recent estimates made by the Chartered Institute of Public Finance and Accountancy, the average cost of local authority residential care for the elderly in England and Wales amounted to approximately $£ 14,500$ per person per annum in fiscal 1993/4, whilst the per capita cost incurred by those in receipt of day care was around $£ 4,000$ per annum. Home care services cost $£ 6.70$ per hour, whilst the standard charge for "meals-on-wheels" was $£ 1.23$ per meal (Chartered Institute of Public Finance and Accountancy, 1994). These averages, however, conceal considerable variations between localities. The south of the country (especially London) is considerably more costly than the north, with annual residential care prices in excess of $£ 20,000$ being common. Even when the form of care is ostensibly the same - the residential home - differences in unit cost arise owing to the varying sizes of the institutions, degrees of disability of the clients, qualifications of staff and so forth. In fact, these operational parameters appear far more influential in determining unit costs that does the form of ownership, public, private or voluntary sector (Davies and Knapp, 1988). 
All the above data, of course, refer to formal care which, as we have seen, only pertains to a minority of disabled persons at present. The major overall cost component - informal care - is unmarketed and therefore particularly difficult to cost, although attempts as imputation have been made. For example, a US cost-of-illness study of senile dementia (Huang, Cartwright et al., 1988) produced a 1985 cost estimate of $\$ 13.3$ billion for formal care, comprising medical/hospital care costs $(48 \%)$, nursing home services costs $(19 \%)$ and social servicc costs $(33 \%)$. Based on survey data relating to nature and duration of care provided by informal carers, and assessing the value of informal care at the professionals' market rate, the authors estimated additional informal care costs of $\$ 31.5$ billion. The authors note that this total is understated in that it makes no allowance for the stress imposed on, and the lost leisure time of, informal carers.

Nuttall et al attempted to resolve both the informal care and the "lack of unit" problem by making assumptions about the general labour requirements necessary to service LTC in their model of the UK (Nuttall, Blackwood et al., 1994). For example, low need subjects were deemed to require 5 hours LTC per week, whilst continuous care required 45 hours. The assumptions made imply labour input weightings of 1, 3, 6 and 9 for low, moderate, regular and continuous care needs, respectively. It accordingly follows from their prevalence estimates, that the increase in labour input necessary to service LTC for all disabled adults over four decades represents a growth of approximately $47 \%$ over the 1991 figure. Over the period, the proportion of these labour resources directed towards those aged 60 years and above will increase from 73 to $83 \%$ of the total.

The most recent attempt at a comprehensive cost audit of LTC in Britain has produced a 1992 figure of approximately $£ 42$ billion for those aged 65 years and over (Laing, 1993). This comprises some $£ 4.6$ billion spent on NHS and local authority institutional care, including around $£ 2$ billion of Income Support expenditure on residents, a further $£ 2$ billion of private spending on private and voluntary sector institutional care and $£ 2.5$ billion representing support (largely publicly-funded) for persons living in private households. The residual (approaching $80 \%$ of the total) represents the imputed value of the labour input provided by informal carers, valued at market rates.

\section{Financing LTC in the future}

As with any commodity, the means to finance LTC can be generated in one of three ways :

(i) Personal entitlement, i.e. from wealth or income;

(ii) Inter-temporal transfer, whereby individuals place their present-period resources at the disposal of an agency, for use by themselves in the future when the need arises. Examples include pensions and insurance schemes, either public or private ;

(iii) Inter-personal transfer, as pertains to charitable giving or non-contributory state benefits such as Attendance Allowance. Under the latter, resources are simply transferred from working taxpayers to non-working disabled beneficiaries. As a sub-set of this category, we might also consider intra-familial transfers, applicable in cases where the responsibilities of carers (e.g. children of aged parents) are defined by family or social obligation. 
Leaving aside the question as to whether the present level of funding in Britain is actually sufficient for present-day LTC needs, the data presented thus far clearly suggest that the former is likely to prove grossly inadequate in servicing needs in the future. This naturally assumes that society will be unwilling to sanction significant long-term erosion in the quality of care. Even the maintenance of existing standards will require the mobilisation of more funding derived from any or all other these three sources.

It should be noted that, within the limits of the law, personal entitlements may be used as and when the individual so desires. Unlike source (i), however, sources (ii) and (iii) must inevitably carry a conditional, eligibility criterion in order for the system to function. With contributory pensions, for example, benefits are only paid by the agency when the individual reaches a pre-specified age. The receipt of non-contributory state benefits requires fulfilment of certain income and wealth conditions. In the case of agencies managing funds to compensate for disabilities, the eligibility criterion will clearly be related, at least in part, to the degree of disability. However, how disabled is disabled? The question is not easily answered. A reliance on the opinion of the subject's medical practitioner is unlikely to produce consistent results, over either time or space. The objective measurement of functional disability in activities of daily living (ADL) has accordingly been a major theme in medical research in recent years and a number of scales have been devised. Unfortunately, no single scale (or even set of scales) has yet won the approval of practitioners (Hopkins, 1992). Moreover, detailed investigations of different ADL scales for specific diseases have often suggested low levels of convergent validity (Shindler, Brown et al., 1993), implying that the degree of disability measured is likely to be a function of the particular ADL scale employed.

For convenience of exposition, we shall consider each of the three sources individually although, in reality, all individuals in Britain are operating within all three structures simultaneously, each to a greater or lesser degree. For reasons which will become clear, it is most unlikely that the solution to the LTC funding problem in the future lies within the province of any one of these sources in isolation.

\section{Personal entitlement}

It can be stated at the outset that paying for LTC out of income is a viable option for only a very few disabled people, and is likely to remain so. Evidence suggests that employment rates amongst the disabled are considerably lower than amongst the able-bodied and that the former are over-represented in low-wage occupations. Even within these occupations, the disabled typically receive less income than their able-bodied counterparts, and all these effects are exacerbated when the degree of disability is more severe (Berthoud, Lakey et al., 1993). In consequence, disability presents the individual with a classic "scissors crisis" - the higher is the need to purchase LTC, then the less likely is the income necessary for purchase to be generated. In the absence of a major government initiative in favour of the employment of the disabled, it is difficult to see how these conditions could be ameliorated, especially in view of the emergence of a general labour surplus in Britain in recent years.

The use of accumulated wealth to fund LTC is likewise reserved only for the few. The distribution of wealth in Britain is particularly uneven, with only $16 \%$ of the population having more than $£ 50,000$ in marketable assets and $32 \%$ holding assets valued at $£ 5,000$ or less (Inland Revenue Statistics and Economics Office, 1993). This having been said, one particular form of wealth held by the elderly is of considerable interest in terms of funding LTC. Of the 6.7 million British households in which the head is either retired or permanently sick, 
3.1 million are outright owner-occupiers of their house. In fact, home ownership in Britain is concentrated in this group, there being 5.2 million outright owner-occupied households in total (Office of Population Censuses and Surveys, 1993). As average house prices are currently around $£ 75,000$ (Department of the Environment, 1993), equity release would seem to offer scope for LTC purchase. Indeed, such release schemes have been operating in Britain for some time (Fleiss, 1985), although not necessarily for this particular purpose.

Although equity release appears workable in principle, there exist evident uncertainties with respect to the future. First, over the past few decades, LTC care costs have increased roughly at the level of wage inflation, a trend to be expected given that labour is the primary input. This cost trend was matched by house price growth until 1990 , when the house price trend peaked and began to fall. With diverging trends, of course, the subject's house effectively represents declining LTC purchasing power. Predicting house prices well into the next century is a foolish endeavour but it is not unreasonable to speculate that (i) increasing demand for LTC could push up care costs disproportionately, (ii) more frequent use of equity release could depress the house price trend, owing to increased supply. Second, it is not evident that home-owners would wish to sacrifice their houses in order to purchase LTC, assuming that some other alternative existed. The house is a both a home and an asset for people other than the disabled person and these other individuals might be reluctant to face dispossession. Persons less seriously disabled might wish to purchase home-based, as opposed to residential, LTC, and the sale of the home would defeat the object of the exercise, especially if the subject viewed the disability as being only temporary.

\section{Inter-temporal transfers}

Private LTC insurance has existed in the USA for some time and, based on the American experience, a number of private insurance plans have become available in the UK in recent years. Market development, however, has proved extremely sluggish (Laing, 1993). The principal factors accounting for poor take-up are the novelty of the product and, possibly of greater importance, the very high cost of, and uncertainty associated with, full-cover policies. A mathematical simulation will demonstrate these latter points.

Suppose that an individual contributes monthly premia of $P$ to an insurance agency. This is invested on his or her behalf at interest rate $i$, until retirement or the onset of disability (whichever is the earlier), $n$ months after the commencement of the scheme. The accumulated fund continues to attract interest during a "grace period" until the onset of disability, $t$ months later. The fund then pays out a regular amount, $R$, over a period of $m$ months, at which point death occurs. The parameter $t$ may, of course, be zero, if payouts begin before retirement. This regular benefit will have to be the cost of LTC at present, adjusted by the assumed rate of inflation, $f$. Using the standard annuity formulae, the problem may be stated thus:

$$
P\left[\frac{(1+i)^{n}-1}{i}\right](1+i)^{t}=R(1+f)^{(n+t)}\left[\frac{1-(1+i)^{-\mathrm{m}}}{i}\right]
$$

which given values for the other parameters, may be solved for $P$. Note that, in order to keep the mathematics manageable, we presume no inflation during the period of payout. In this basic formulation only one disability state and its corresponding level of benefit is allowed. In reality, it is much more likely that individuals will pass through a number of disability 
states, each of incrcasing severity and entailing increasing LTC costs. The solution is therefore to consider a set of individual annuities, all formulated as above, each appropriate to a higher level of benefit. The second annuity begins to pay out after departure from the first disability state, and so on. In our model, three disability states are assumed.

For the purpose of simulation, we make the following assumptions. First, the interest rate is set to $6 \%$ per annum, as is conventional in UK economic evaluations. Second, the annual rate of inflation is set to $2.6 \%$, the average rate of growth of personal disposable income for the period 1953-7 to 1988-92 (Central Statistical Office, 1994). Third, we shall employ disability-based life expectancy estimates for Great Britain (Bebbington, 1992) and assume that the OPCS disability categories 1-4 constitute mild disability, with 5-7 and 8-10 being moderate and severe disability, respectively. Fourth, the annual LTC cost of services for mild disability we shall take to be $£ 2,000$ : based on the cost data presented earlier, this represents a daily meal and a few hours of home help each week. Moderate disability is assumed to entail an annual cost of $£ 4,000$, approximately equivalent to the cost of daycare. Severe disability, we assume, requires residential carc, at the present annual cost of $£ 14,500$. Fifth, no allowance is made for transactions costs or profit to the insuring agency. Finally, we assume a retirement age of 65 years.

Given that the life expectancy of females is longer than that of males, and that more female years will be lived in one or more of the disability states, their required premia are considerably higher. For males entering the insurance scheme at 20,30, 40 and 50 years of age, the required annual premia are $£ 351$, 5503 , $£ 764$ and $£ 1252$, respectively. For females, the necessary premia are higher, at $£ 489$, $£ 694$, $£ 1065$ and $£ 1800$ for the above ages. We take the case of the 40 -years old male (premium $\$ 764$ ) as a base estimate to test the impact of parameter changes under a number of scenarios:

(i) A $10 \%$ fall in the long-term interest rate raises the required annual premium by $14.0 \%$

(ii) If the demand for LTC increases in the future, it is conceivable that its costs may increase at a higher rate. A $10 \%$ increase in the assumed rate of LTC inflation raises the required premium by $8.2 \%$.

(iii) In recent years, European economies have exhibited an interest in lowering the age of retirement, partly as a response to prevailing high unemployment levels. A lowering of the age of retirement to 60 years would increase the required premium by $11.2 \%$.

(iv) It was noted earlier that the definition of disability to determine eligibility has yet to be made precise. Suppose that our classification of the disability states was made more liberal, and that individuals entered moderate and severe disability at OPCS states 4 and 7 , respectively (rather than at 5 and 8 ). Such a re-definition would require a premium rise of $18.8 \%$, suggesting that insurance policy design will be particularly sensitive to the choice of the ADL measure used to trigger benefits.

(v) Over time, increases in life expectancy must be anticipated and data from the USA suggest a three-year increase between 1970 and 1980, although such high growth cannot be sustainable indefinitely. The same data also indicate that disability-free life expectancy has remained almost static (especially for females) and that the extra years which have been gained represent extra years lived with varying degrees of disability (Crimmins, Saito et al., 1989). We shall approximate such a change within the model by assuming one extra year of life in the "grace period" and one extra year for each of the three disability states. Such a change would raise the required annual premium by $55.6 \%$. 
(vi) As noted earlier, LTC residential costs vary considerably on a regional basis, Residential care to cater for severe disability costing $£ 25,000$ per annum, as opposed to the assumed $£ 14,500$, would require an upward premium revision of $34.0 \%$.

It should be noted that the $\$ 764$ premium required in the base estimate represents approximately $10 \%$ of average personal disposable income in the UK at present. Under the plausible assumption about parameter changes made above, this proportion could rise considerably. Policy modelling of this sort, of course, can only provide "order of magnitude" estimates. Nevertheless, it seems reasonable to conclude that realistic, full-cover insurance against LTC is a very expensive proposition. The simulation demonstrates that the required premia rise steeply with age. Prices are lowest at the earliest starting ages, although this is typically also a time when individual's incomes are low and other family commitments, such as care of children, are prevalent. At this time, the risk being insured against is occurring far in the future, and is thus perceived of lesser importance. By middle age, when such factors are less influential, the required premia increase and potential customers have found the entry price for policies which offer the degree of coverage which they would ideally like simply too high to be afforded. On the other hand, affordable policies cannot offer the requisite degree of coverage and are likewise deemed unattractive.

It should also be noted that insurance companies have experienced considerable difficulties in policy design; indeed, our simulation suggests that required premia are extremely sensitive to not-implausible changes in key parameter values. UK companies are also wary of the threats posed by adverse selection and moral hazard which have been observed in the American market (Garber, 1988). The asymmetry of prior information between client and insurance company is considerable in the disability case and obtaining the relevant information is expensive from the company's point of view. The use of deductibles may ameliorate the moral hazard problem, although this tends to diminish the attractiveness of the insurance product. The presence of insurance also disinclines familial carers, who might otherwise play a role in LTC support, from assuming such responsibilities.

\section{Inter-personal transfers}

Two points may be made with respect to the voluntary sector. First, its contribution to social welfare provision in general is modest in comparison with that made by the state and the informal sector. Second, the growth in activity has been sluggish in the past, despite the targeting of official support on this sector (Glennerster, 1993). Results from pilot studies undertaken during the late-1980s suggest that "pump-priming" public funds, designed to develop the voluntary sector, rarely succeed in achieving long-term autonomous viability and the majority of voluntary services established with such support continued to depend on public finance for their continued operation. Perhaps more surprisingly, the increased use of voluntary labour does not appear to achieve noticeable cost economies, as such a use requires more intensive inputs from salaried co-ordination staff. This having been said, examples of cost-effective voluntary sector initiatives certainly do exist. Interestingly enough, these tend to be the smaller-scale projects with modest aims, for example, the provision of "sitting" services to permit short-term relief for informal carers (Department of Health Social Services Inspectorate, 1991).

The extrapolation of demographic trends alerts us to the likelihood of future problems in the informal sector (intra-familial transfers). First, informal carers are principally women. However, a growing proportion of women are economically-active participants in 
the labour market and may be unwilling to play the "traditional" caring role in the future. Second, an increasing rate of divorce will mean proportionately fewer partners and "inlaws" to act as carers. Third, with an ageing population, more and more carers may themselves be affected by age-related infirmities requiring care. Fourth, average family sizes are diminishing, fifth, younger generations exhibit greater geographical mobility that their parent: both these factors will reduce the likely numbers of future proximate informal carers. On the positive side, further increases in unemployment would tend to stimulate the supply of informal care, as the opportunity cost of informal care for persons faced with long-term unemployment is lower than for employed people.

Assuming that material growth in the UK maintains the steady progress of the post-war period, the funding of future LTC by transfer payments from the state probably poses more political questions than it does economic ones. The UK presently maintains a public sector of a significantly smaller size that most of its European neighbours, and even increasing the state's role in funding LTC in the future would not alter that position (Whynes, 1993). The imponderable in the equation is ideology. Forty years ago, Britain was embarking on the establishment of a comprehensive welfare state, aiming to providing social support "from the cradle to the grave". In realising this aim, ever-increasing tax burdens appeared to cause little concern to the electorate. In recent years, the prevailing ideology appears to have favoured dismantling much of the edifice so created. As to forty years hence, who can tell? By that time, it is, of course, probable that the UK's LTC care issues will be resolved in a European rather than a national arena, assuming that the European Union continues to follows its charted course.

\section{Conclusions}

From the foregoing discussion, a number of propositions about the future appear reasonable. First, the voluntary and charity sectors will continue to play the minor role in service provision which they have played in the past. Second, in the absence of substantial shifts in government policy, only a minority of individuals in the economy will be in a position to make their own private provision for LTC, individuals with sufficient income or wealth to fund insurance and equity release schemes. Third, for the majority, LTC will continue to be the province of state benefits and informal care (intra-familial transfers).

With respect to the second proposition, market expansion is difficult, if only because the time when LTC insurance premia would be low (entry into the labour market) is the time when the individual has little concern for distant possibilities. Individuals become progressively more interested in LTC as they age, by which time the policies are becoming progressively more expensive. Low-cost policies inevitably mean low payouts, which are unattractive to potential purchasers. Nevertheless, the role of private provision may be capable of development through a variety of means. A tax-based, redistribution of income, for example, would be likely to increase the size of the market, although at the expense of increased tax burdens on the higher-income groups. In theory, tax relief on LTC insurance premia should have a similar effect, although evidence suggests the effect could actually be perverse. A study of the effect of tax relief on general private health insurance premia for the elderly in the UK suggested a price elasticity of demand of virtually zero, with gains to insurance companies being insufficient to compensate for the resultant loss in government revenue (Propper and Maynard, 1990). Perhaps the strongest incentive for developing the private sector which the government could offer would be to declare its intention to 
withdraw from LTC in the future. For obvious political reasons, such a declaration is unlikely although individuals naturally construct purchasing intentions on the basis of their perceptions of likely government conduct.

Extending the present system of National Insurance to cover LTC is perhaps the most natural way of resolving the finance problem, as regards the majority of the population. Indeed, this is the way already chosen by other European countries, such as France, Germany and the Netherlands. The mathematics of a public funded scheme are equivalent to those explored earlier in the private insurance case, although scope additionally exists for degrees of cross-subsidisation from other tax revenues. Clearly, the longer the lead time for such a system, then the lower will be the annual burden of contribution on both the employer and employee. As a piece of social engineering, such an introduction would be comparable with the 1975 Social Security Pensions Act, which had a lead time of approximately $20-25$ years.

The main obstacle to the introduction of such a scheme would be a lack of political vision on the part of the government. If I may end on a personal note, I have the strong suspicion that this vision will prove lacking in the future and that, as has always been the case in the past, the informal sector will be obliged to accommodate the very substantial shortfall.

\section{REFERENCES}

AUDIT COMMISSION, Community Care: Managing the Cascade of Change (Paper 91/78), 1991. London, Audit Commission.

BEBBINGTON, A. C., "Expectation of life without disability measured from the OPCS disability surveys", in J.-M. Robine, M. Blanchet and J. E. Dowd (ed.), Health Expectancy, 1992, London, Office of Population Censuses and Surveys, pp.23-24.

BERTHOUD, R., LAKEY, J. and McKAY, S., The economic problems of disabled people, 1993. London, Policy Studies Institute.

CENTRAL HEALTH MONITORING UNIT, The health of elderly people, Volume 1, 1992. London, HMSO.

CENTRAL STATISTIC OFFICE, Economic trends annual supplement, 1994 edition, 1994. London, HMSO.

CHARTERED INSTITUTE OF PUBLIC FINANCE AND ACCOUNTANCY, Personal social services statistics, 1994-95 estimates, 1994. London, CIPFA.

CRIMMINS, E. M., SAITO, Y. and INGEGNERI, D., "Changes in life expectancy and disability-free life expectancy in the United Statcs", Population and Development Review, 15(2), 1989, pp. 235-267.

DAVIES, B. and KNAPP, M., "Costs and residential social care", in I. Sinclair (ed.), Residential care: the research reviewed, 1988. London, HMSO, pp. 293-378.

DEPARTMENT OF HEALTH, Health and personal social services statistics for England, 1993. London, HMSO.

DEPARTMENT OF HEALTH SOCIAL SERVICES INSPECTORATE, Carer support in the community, 1991. London, HMSO.

DEPARTMENT OF THE ENVIRONMENT, Housing and construction statistics, 1982-1992, 1993. London, HMSO. 
FLEISS, A., Home ovnership alternatives for the elderly, 1985. London, Department of the Environment, HMSO.

GARBER, A., "Cost containment and financing long term care of the elderly", Journal of the American Geriatrics Society, 36, 1988, pp. 335-361.

GLENNERSTER, H., "Paying for welfare: Issues for the nineties", 1993, in N. Deakin and R. Page (ed.) The costs of welfare, Aldershot, Avebury, pp. 13-28.

HOFMAN, A., ROCCA, W., BRAYNE, C. et al., "The prevalence of dementia in Europe : a collaborative study", International Journal of Epidemiology, 20, 1991, pp. 736-745.

HOPKINS, A., Ed., Measures of the quality of life and the uses to which such measures may be put, 1992. London, Royal College of Physicians of London.

HUANG, L. F., CARTWRIGHT, W. S. and HU, T.-W., "The economic cost of senile dementia in the United States, 1985", Public Health Reports, 103(1), 1988, pp. 3-7.

INLAND REVENUE STATISTICS AND ECONOMIC OFFICE, Inland revenue statistics, 1993, 1993. London, HMSO.

LACZKO, F. and NODEN, S., "Combining paid work with eldercare: the implications for social policy", Health and Social Care, 1(2), 1993, pp. 81-89.

LACZKO, F. and PHILLIPSON, Changing work and retirement: social policy and the older worker, 1991. Milton Keynes, Open University Press.

LAING, W., Financing long term care: the crucial debate, 1993. London, Age Concern England.

LEVIN, E., SINCLAIR, I. and GORBACH, P., Families services and confusion in old age, 1989. Aldershot, Averbury.

MARTIN, J., MELTZER, H. and ELIOT, D., The prevalence of disability among adults (OPCS surveys of disability in Great Britain, Report 1), 1988. London, HMSO.

NUTTALL, S. R., BLACKWOOD, R. J. L., BUSSELL, B. M. H., et al., "Financing long-term care in Great Britain", Journal of the Institute of Actuaries, 121(1), 1994, pp. 1-68.

OFFICE OF HEALTH ECONOMICS, Compendium of Health Statistics, 1992. London, Office of Health Economics.

OFFICE OF POPULATION CENSUSES AND SURVEYS, 1991 census: housing and availability of cars: Great Britain, 1993. London, HMSO.

OFFICE OF POPULATION CENSUSES AND SURVEYS, 1991-based national population projections, Series PP2, No. 18, 1993. London, HMSO.

PARKER, G., With due care and attention: a review of the literature on informal care, 1990. London, Policy Studies Institute.

PEARSON, N. D., An assessment of relief hospital admission for elderly patients with dementia", Health Trends, 20, 19988, pp. 120-121.

PROPPER, C. and MAYNARD, A., "Whither the private health care sector?" in A. J. Culyer, A. K. Maynard and J. W. Posnett (ed.) Competition in health care: reforming the NHS, Basingstoke, MacMillan : pp. 48-66.

SCHNEIDER, J., KAVANAGH, S., KNAPP, M., BEECHAM, J. and NETTEN, A., "Elderly people with advanced cognitive impairment in England: resource use and cost", Ageing and Society, 13, 1993, pp. 27-50.

SECRETARIES OF STATE FOR HEALTH, Caring for People (Cmnd 849), 1989. London, HMSO. 
SHINDLER, J. S., BROWN, R., WELBURN, P. and PARKES, J. D., "Measuring the quality of life of patients with Parkinson's disease", in S. R. Walker and R. M. Rosser (ed.), Quality of life assessment: key issues of the 1990s, Dordrecht, Kluwer Academic Publishers, 1993, pp. 289-300.

WHYNES, D. K., "Economic recession and the welfare state", Economics and Business Education, 1(4), 1993, pp. 172-177.

WHYNES, D. K., "Long term care for the elderly", in Association of British Insurers (ed.), Risk, Insurance and Welfare, London, ABI, 1995, pp. 26-36. 